\title{
Transapical aortic valve implantation using a Symetis Acurate self-expandable bioprosthesis: initial outcomes of 10 patients
}

\author{
Marcin Misterski ${ }^{1}$, Mateusz Puślecki ${ }^{1}$, Marek Grygier ${ }^{2}$, Anna Olasińska-Wiśniewska², Maciej Lesiak ${ }^{2}$, \\ Aleksander Araszkiewicz², Barłomiej Perek ${ }^{1}$, Aneta Choręziak ${ }^{1}$, Jacek Lindner ${ }^{1}$, Anna Komosa ${ }^{2}$, Piotr Buczkowski ${ }^{1}$, \\ Marcin Ligowski ${ }^{1}$, Sławomir Katarzyński ${ }^{1}$, Marek Jemielity ${ }^{1}$ \\ ${ }^{1}$ Department of Cardiosurgery and Transplantology, Poznan University of Medical Sciences, Poznan, Poland \\ 2Department of Cardiology, Poznan University of Medical Sciences, Poznan, Poland
}

Videosurgery Miniinv 2017; 12 (2): 172-177 DOI: https://doi.org/10.5114/wiitm.2017.67481

\begin{abstract}
Introduction: Transapical aortic valve implantation (TA-AVI) has been widely introduced for treatment of patients with severe aortic stenosis in the last decade. Here we report our first clinical experience with 10 patients using the second-generation transapical Symetis Acurate TA aortic valve designed for transapical implantation.

Aim: To evaluate the results of transapical access in transcatheter aortic valve implantation (TAVI) among patients with unsuitable vascular access.

Material and methods: All patients had been assessed by a local heart team and were disqualified from surgical aortic valve replacement (AVR) and the transfemoral TAVI approach. Mean age was $75.4 \pm 3.9$ years (range: 68-80), with $20 \%$ being female. Logistic EuroSCORE (European System for Cardiac Operative Risk Evaluation) and STS (Society of Thoracic Surgeons) were $15.4 \pm 8.9 \%$ and $20.5 \pm 4.5 \%$, respectively.

Results: All implantations were performed successfully in the intra-annular and subcoronary position. There were no conversions to surgical AVR. All patients survived 30-day follow-up. No strokes or transient ischemic attacks were reported. There was no need for pacemaker implantation and none of the patients demonstrated moderate or significant paravalvular leakage. The mean aortic gradients improved significantly from a baseline of $57.0 \pm 19.2 \mathrm{~mm} \mathrm{Hg}$ to a 30-day value of $14.2 \pm 4.1 \mathrm{~mm} \mathrm{Hg}$.

Conclusions: Our initial clinical results indicate satisfactory functionality in patients after trans-apical implantation of the Symetis Acurate aortic valve. The procedure of implantation seems to be straightforward and may be considered in patients in whom a transfemoral approach is not a good option.
\end{abstract}

Key words: aortic stenosis, transcatheter aortic valve implantation, transapical valve implantation, Symetis Acurate valve.

\section{Introduction}

Trans-catheter aortic valve implantation (TAVI) has evolved rapidly in the last decade and has become a routine procedure in many centers for treatment of high-risk patients who are not suitable candidates for surgical aortic valve replacement (SAVR) [1]. The potential benefits are minimally invasive access and off-pump valve implantation. However, SAVR, even in elderly patients, is still a good alternative, presenting excellent results and 30-day mortality rates of about $2 \%$ [2]. The TAVI should be reserved for patients who are not surgical candidates and for extremely high-risk patients as far as the EACTS and ESC guidelines are concerned [3]. The TAVI can be performed by using a retrograde transfemoral (TF),

\section{Address for correspondence}

Marcin Misterski MD, PhD, Department of Cardiosurgery and Transplantology, Poznan University of Medical Sciences, $1 / 2$ Długa St,

61-841 Poznan, Poland, phone: +48 606955 354, e-mail: mister@poczta.onet.pl 
transaortic/direct aortic, trans-subclavian, transcarotid or antegrade transapical (TA) approach. The transfemoral method is the most frequently chosen approach as it is thought to be the least invasive. However, [4] problems with vascular access or anatomical malformations still disqualify some patients - an alternative approach should be then selected. The first generation of TAVI valves demonstrated its safety and effectiveness in various clinical trials [5]. The next-generation of transcatheter valves improved the results by way of feasibility for anatomically correct positioning, repositioning, and retrievability [6].

Here we report our clinical experience with the first 10 patients using the second-generation transapical valve Symetis Acurate (Symetis Inc., Switzerland). All patients were initially disqualified from the femoral approach.

\section{Aim}

The aim of the study was to evaluate the results of transapical access in TAVI among the patients with unsuitable vascular access.

\section{Material and methods}

\section{Study group}

From August 2014 until January 2016, a total of 10 patients were operated on using the Symetis Acurate valve. Mean age was $75.4 \pm 3.9$ years (range: 68-80) with $20 \%$ being female. Logistic EuroSCORE (European System for Cardiac Operative Risk Evaluation) and STS (Society of Thoracic Surgeons) were $15.4 \pm 8.9 \%$ and $20.5 \pm 4.5 \%$, respectively. Patients' characteristics are presented in Table I.

All patients preoperatively presented as class II or III in accordance with the New York Heart Association (NYHA) classification. The clinical decision to perform TAVI by the transapical route (TA-TAVI) was settled by a multidisciplinary heart team after discussing all available options. All patients were informed about the proposed method of treatment individually and signed informed consent before the procedure.

\section{Methods (Trans-catheter Valve Implantation Technique)}

All procedures were done under general anesthesia in a hybrid room. Implants were performed off- pump under fluoroscopic guidance with transesophageal echocardiography as an additional control. Cardiopulmonary bypass was prepared for emergency intervention if necessary. All the procedures were performed by the same heart team involving two cardiac surgeons, a cardiologist, cardiac anesthetists, a perfusionist, and a scrub nurse. A temporary endocardial electrode was placed into the right ventricle from the jugular vein.

Apical access was obtained using a left anterior mini-thoracotomy that was usually performed at the fifth or sixth intercostal space (Photo 1). The skin incision was approximately $6 \mathrm{~cm}$ long. Soft tissue retractors were used for rib spreading. Once the left ventricular apex was visualized and exposed, two purse-string sutures of 3-0 polypropylene were

Table I. Preoperative patients' demographics $(n=10)$

\begin{tabular}{|lc|}
\hline Parameter & \multicolumn{1}{c|}{ Result } \\
\hline Age [years] & $\begin{array}{c}75.4 \pm 3.9 \\
\text { (range: } 68-80)\end{array}$ \\
\hline Logistic EuroSCORE (\%) & $15.4 \pm 8.9$ \\
\hline STS score (\%) & $20.5 \pm 4.5$ \\
\hline Re-do procedure, $n$ (\%) & $4(40)$ \\
\hline Female, $n$ (\%) & $2(20)$ \\
\hline Left ventricular EF (\%) & $57.6 \pm 10.8$ \\
\hline Peripheral vascular disease, $n$ (\%) & $7(70)$ \\
\hline Carotid artery stenosis, $n$ (\%) & $5(50)$ \\
\hline Stroke, $n$ (\%) & None \\
\hline $\begin{array}{l}\text { Chronic obstructive pulmonary disease, } \\
n(\%)\end{array}$ & $2(20)$ \\
\hline $\begin{array}{l}\text { Mean aortic gradient before procedure } \\
\text { [mm Hg] }\end{array}$ & $57.0 \pm 19.2$ \\
\hline $\begin{array}{l}\text { Maximal aortic gradient before procedure } \\
\text { [mm Hg] }\end{array}$ & $91.6 \pm 23.2$ \\
\hline Aortic valve opening area [cm ${ }^{2}$ ] & $0.71 \pm 0.07$ \\
\hline \begin{tabular}{l} 
NYHA class before procedure, $n$ : \\
\hline I
\end{tabular} & 0 \\
\hline IV & 2 \\
\hline
\end{tabular}

STS - Society of Thoracic Surgeons, EF-ejection fraction, NYHA - New York Heart Association functional classification. Data are presented as mean \pm standard deviation or number/percentage. 


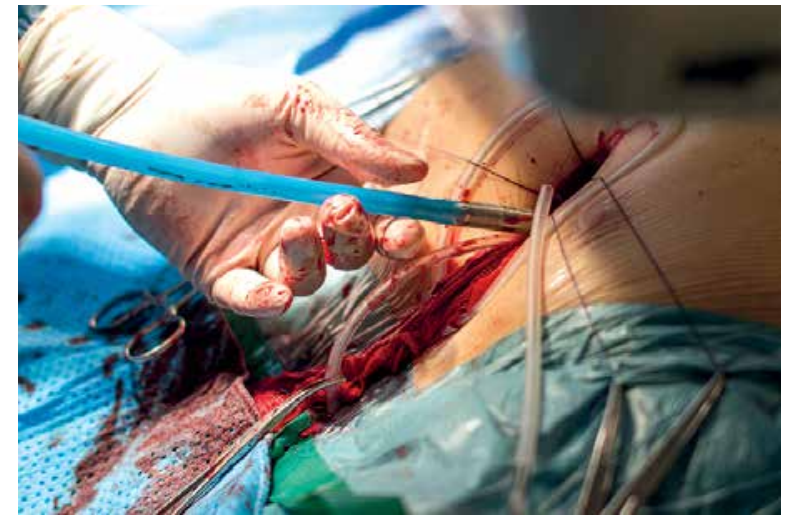

Photo 1. Apical access gained by a left anterior mini-thoracotomy in the fifth or sixth intercostal space

placed and reinforced with Teflon pledgets. The optimal C-arm angulation was established according to the DynaCT preoperative measurements. In addition, a femoral arterial $6 \mathrm{Fr}$ sheath was inserted and a pigtail catheter was introduced into the ascending aorta. The apex was punctured under direct visualization of the surgeon and a soft guide wire was introduced across the stenotic aortic valve under fluoroscopic control. The 6 Fr sheath was inserted into the left ventricle and a left Amplatz catheter was introduced over the soft wire. The soft wire was subsequently exchanged for a stiff wire (Amplatz Super stiff, 0.35”, $260 \mathrm{~cm}$, Boston Scientific). After

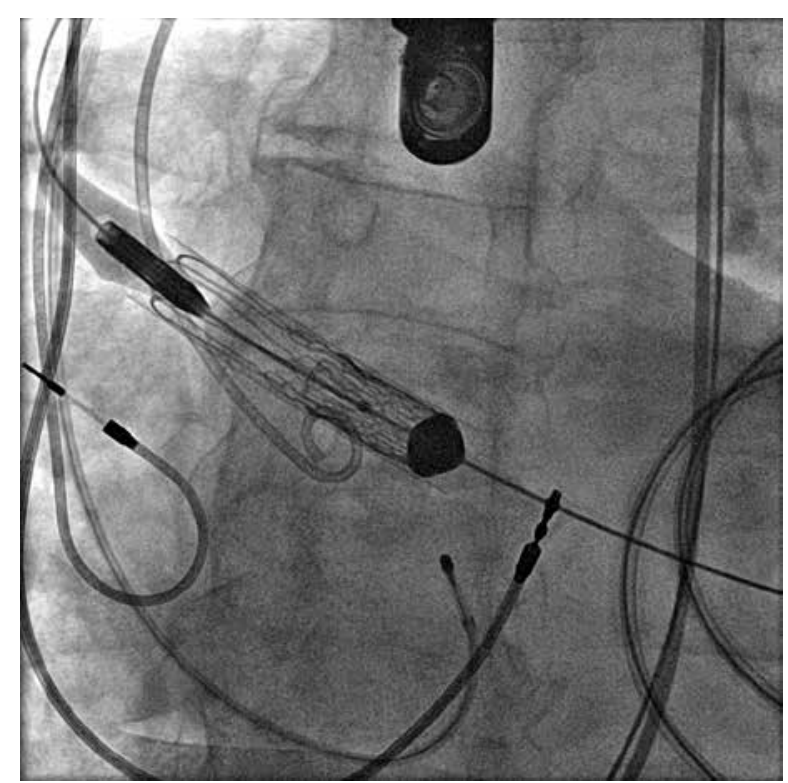

Photo 2. Positioning of a Symetis Acurate in the aortic annulus under fluoroscopic guidance guidewire placement a $14 \mathrm{Fr}$. sheath balloon valvuloplasty was performed during rapid ventricular pacing with an Osypka balloon (Osypka AG, Germany) sized $1 \mathrm{~mm}$ less than the measured diameter of the annulus. At the same time, a preselected valve was crimped and its delivery system was de-aired using carbon dioxide insufflation. Aortic valvuloplasty was performed under ventricular rapid pacing of $180 /$ min once the systemic systolic pressure dropped below $50 \mathrm{~mm} \mathrm{Hg}$. The delivery system was bluntly introduced and positioned in the aortic annulus (Photo 2). By rotating radiopaque visibility markers, the anatomical position was reached. Step one had been performed - the stabilization arches and upper crown were released and a final angiography confirmed the proper valve position. The tactile feedback facilitated proper annular orientation. Finally, the "safety button" was removed and step two of the implantation was completed. Once the Symetis Acurate valve was fully deployed (Photo 3) and the delivery system removed, the apical purse-string sutures were tied. After introducing an $18 \mathrm{~F}$ chest tube drain into the left pleural cavity, routine chest wall closure was performed and the patient was transferred to the postoperative intensive care unit for early extubation.

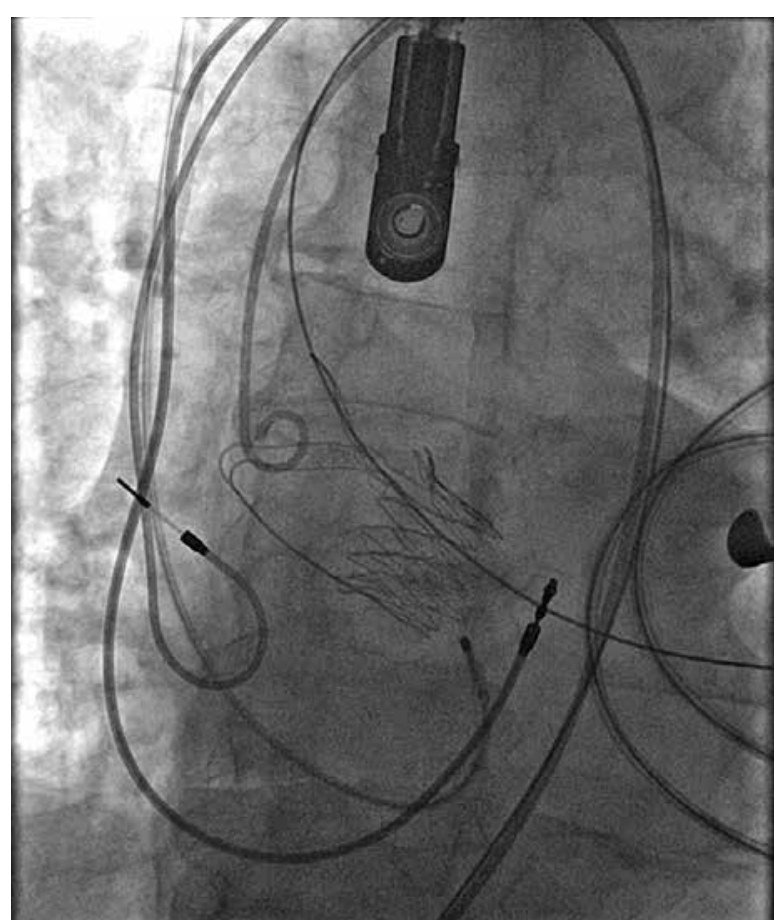

Photo 3. Final valve deployment - last step of implantation process 


\section{Statistical analysis}

For statistical analysis all relevant data were recorded. Continuous variables are presented as the mean plus the standard deviation. Categorical data are expressed as proportions.

\section{Results}

All 10 patients survived the surgery and all valves were implanted successfully. There were no conversions to open heart surgery and all valve implantations were performed off-pump. In two cases a post-dilatation was performed to optimize the procedural result. The $S, M$ and $L$ valves were implanted in 1, 5 and 4 patients respectively. There was one intraoperative apical bleeding event requiring additional surgical suture placement which was successfully managed. One patient was re-operated on because of increased postoperative drainage due to intercostal small vessel bleeding, which was localized and coagulated. There were no neurological complications of the procedure. Postoperative kidney failure requiring temporary hemodialysis was observed in one patient. All patients were discharged between the $7^{\text {th }}$ and $10^{\text {th }}$ postoperative day. There was no need for permanent pacemaker implantations. A trivial paravalvular leak was noted in 4 patients.

In the 30-day postoperative period no deaths were recorded, but one patient was urgently treated for an abdominal aortic aneurysm (AAA) rupture (Tables II and III).

\section{Discussion}

This paper presents our first experience with transapical trans-catheter aortic valve implantations (TA-TAVI). Our center established the TAVI program in 2012. Following initial experience with CoreValve (Medtronic) and Lotus Valve (Boston Scientific), using the retrograde femoral and direct aortic access with encouraging results, we began with the transapical (TA) procedure in September 2014. All patients who were operated on using the transapical approach were selected only when there was unsuitable vascular access. Although we continue to advocate transfemoral access as the first-line approach because of its minimally invasive nature, the transapical anterograde access has its advantages and benefits [7]. The superiority of one method over the other is not proven, and a randomized trial will probably never be performed. The potential advantages associated with an anterograde approach are many, and include the following: minimal aortic manipulation reflected in the low complication rates for strokes; less limitation regarding the sheath diameter, which avoids excessively tight valve crimping that can impact the long-term valve durability; and finally, as a result of shorter "wire" distance, the valve positioning seems to be easier and may lead to better procedural results $[8,9]$.

The Symetis Acurate valve is a self-positioning porcine bioprosthesis. The self-expanding nitinol stent is composed of three stabilization arms providing valve stabilization in the ascending aorta during deployment. The porcine tissue valve is sewn into a nitinol stent and is covered by a PET skirt. The valve is designed to obtain an intra-annular, sub-coronary position. Tactile feedback is achieved with a distal part of the stent, called the upper crown, which when optimally positioned produces a slight feeling of tension on the delivery system to secure-

Table II. Intra-operative data $(n=10)$

\begin{tabular}{|lc|}
\hline Variable & Result \\
\hline Successful valve implantation, $n(\%)$ & $10(100)$ \\
\hline $\begin{array}{l}\text { Acurate sizes, } n(\%): \\
\text { Small }\end{array}$ & $1(10)$ \\
\hline $\begin{array}{l}\text { Medium } \\
\text { Large }\end{array}$ & $5(50)$ \\
\hline $\begin{array}{l}\text { Mean aortic gradient after procedure } \\
\text { [mm Hg] }\end{array}$ & $14.2 \pm 4.1$ \\
\hline $\begin{array}{l}\text { Maximal aortic gradient after procedure } \\
{\left[\begin{array}{l}\text { mm Hg] } \\
\text { Bleeding, } n \text { (\%): }\end{array}\right.}\end{array}$ \\
\hline $\begin{array}{l}\text { Major } \\
\text { Minor }\end{array}$ \\
\hline
\end{tabular}

Data are presented as mean \pm standard deviation or number/percentage.

Table III. NYHA class after TAVI

\begin{tabular}{|lcc|}
\hline NYHA before & NYHA after & Patients, $n(\%)$ \\
\hline II & I & $2(20)$ \\
\hline III & II & $8(80)$ \\
\hline
\end{tabular}

NYHA - New York Heart Association functional classification. Data are presented as number/percentage. 
ly lock it in place. The delivery catheter is designed for an easy two-step sheath-less implantation which facilitates the release of stabilization arms and the upper crown in step one [10], while step two deploys the body of the valve. The Symetis Acurate valve is available in three different sizes which are described as $S, M$, and $L$ and which cover an aortic annulus diameter from 21 to $27 \mathrm{~mm}$.

The Symetis Acurate represents a significant improvement in almost every field of TAVI research over the first generation transapical TAVI valves [10]. The important issue to address are paravalvular leaks (PVL) and their influence on patient survival, which are already well known. A general consensus is that mild leakage is well tolerated, but moderate and severe PVL can have a direct impact on the 30day hospital mortality and long-term survival of the patient [11]. The data from the German TAVI registry confirm this statement and highlight the necessity of avoiding residual leaks after TAVI procedures [12]. As already mentioned, the observed rate of PVL among our patients is very low due in part to the specific design of stents with a polyester skirt that cultivate self-sealing to the native valve and hinder paravalvular leakage. Current drawbacks for implantation of first generation TAVI devices, especially CoreValve, are the frequent occurrences of new AV blocks that necessitate pacemaker implantation $[11,13]$. Based on our clinical data and many other referenced publications, the need for new pacemaker implantation in patients following Accurate implantation is infrequent. The final effect of a small $6 \mathrm{~cm}$ long thoracotomy for the placement of an Accurate valve is a better alternative to a pacemaker implantation that was observed in $7.5 \%$ of patients in Kempfert's study [14] in comparison with the majority of transfemoral studies using different valves. The greatest potential advantage of the Acurate is the feasibility of achieving commissural alignment and precise anatomical positioning. This could alleviate the need for future coronary $\mathrm{PCl}$ procedures. Additional interventional procedures are potentially dangerous, especially when a valve strut is in front of a coronary ostium with concomitant severe calcification, further increasing the odds for a coronary obstruction. The commissural alignment may be beneficial, although there is no scientific evidence to support this [10, 14].

Significant simplification is associated with a $\mathrm{C}$-arm position. While achieving the annulus plane the operators leave the C-arm in one position throughout the whole procedure. This is especially useful for physicians who have limited C-arm experience. Last but not least, the preparation of the valve seems to be easy. The crimping phase is simple and introduction of a three-step procedure can be managed by a physician or a nurse in a short time [15].

The short-term results of the first registry of Acurate TA proved a safety and efficacy profile comparable, if not improved in some aspects, with previously approved transcatheter aortic valve implantation devices [16]. Comparison of two valve systems - Acurate TA vs Sapien XT - in a propensity score matched analysis demonstrated comparable hemodynamic performance and clinical outcome. The self-expendable valve required more frequent post-ballooning without affecting the safety profile [17]. Meanwhile more than 3000 patients have been treated worldwide with transapical and transfemoral Symetis valves, and additional registries are currently under investigation [18].

\section{Conclusions}

This report documents the first experience in Wielkopolska with the anterograde Symetis Acurate second generation valve. The functional hemodynamic outcomes are very good, with low residual gradients and very low rates of serious paravalvular leaks. With its promising initial results and relatively low rate of complications, the Symetis Acurate seems to be a good option for patients with poor femoral access.

\section{Conflict of interest}

The authors declare no conflict of interest.

\section{References}

1. Leon MB, Smith CR, Mack M, et al. Transcatheter aortic-valve implantation for aortic stenosis in patients who cannot undergo surgery. N Engl J Med 2010; 363: 1597-607.

2. Grossi EA, Schwartz CF, Yu PJ, et al. High-risk aortic valve replacement: are the outcomes as bad as predicted? Ann Thorac Surg 2008; 85: 102-6; discussion 107.

3. Vahanian A, Alfieri O, Al-Attar N, et al. Transcatheter valve implantation for patients with aortic stenosis: a position statement from the European Association of Cardio-Thoracic Surgery (EACTS) and the European Society of Cardiology (ESC), in collaboration with the European Association of Percutaneous Cardiovascular Interventions (EAPCI). Eur Heart J 2008; 29: 1463-70. 
4. Piazza N, Grube E, Gerckens U, et al. Procedural and 30-day outcomes following transcatheter aortic valve implantation using the third generation (18 Fr) corevalve revalving system: results from the multicentre, expanded evaluation registry 1-year following CE mark approval. Eurolntervention 2008; 4: 242-9.

5. Thomas M, Schymik G, Walther T, et al. Thirty-day results od a SAPIEN aortic bioprosthesis European outcome (SOURCE) Registry: a European registry of transcatheter aortic valve implantation using the Edwards SAPIEN valve. Circulation 2010; 122: 62-9.

6. Grube E, Schuler G, Buellesfeld L, et al. Percutaneous aortic valve replacement for severe aortic stenosis in high-risk patients using the second- and current third-generation selfexpanding CoreValve prosthesis: device success and 30-day clinical outcome. J Am Coll Cardiol 2007; 50: 69-76.

7. Walther T, Dewey T, Borger MA, et al. Transapical aortic valve implantation: step by step. Ann Thorac Surg 2009; 87: 276-83.

8. Kempfert J, Walther T, Borger MA, et al. Minimally invasive offpump aortic valve implantation: the surgical safety net. Ann Thorac Surg 2008; 86: 1665-8.

9. Kempfert J, Falk V, Schuler G, et al. DynaCT during minimally invasive off-pump transapical aortic valve implantation. Ann Thorac Surg 2009; 88: 2041.

10. Kempfert J, Rastan AJ, Beyersdorf F, et al. Trans-apical aortic valve implantation using a new self-expandable bioprosthesis: initial outcomes. Eur J Cardiothorac Surg 2011; 40: 1114-9.

11. Nuis RJ, van Mieghem NM, van der Boon RM, et al. Effect of experience on results of transcatheter aortic valve implantation using a Medtronic CoreValve System. Am J Cardiol 2011; 107: 1824-9.

12. Abdel-Wahab M, Zahn R, Horack M, et al. Aortic regurgitation after transcatheter aortic valve implantation: incidence and early outcome. Results from the German transcatheter aortic valve interventions registry. Heart 2011; 97: 899-906.

13. Bleiziffer S, Ruge H, Horer J, et al. Predictors for new-onset complete heart block after transcatheter aortic valve implantation. JACC Cardiovasc Interv 2010; 3: 524-30.

14. Kempfert J, Treede H, Rastan A, et al. Transapical aortic valve implantation using a new self-expandable bioprosthesis ( ACURATE TA'M): 6-month outcomes. Eur J Cardiothorac Surg. 2013; 43: 52-7.

15. Zembala M, Piegza J, Wacławski J, et al. Symetis Acurate Transapical Aortic Valve: the initial experience with a second generation of trancatheter aortic valve replacement device. Kardiol Pol 2014; 72: 187-93.

16. Kempfert J, Holzhey D, Hofmann S, et al. First registry from the newly approved Acurate TA ${ }^{\mathrm{TM}}$ TAVI system. Eur I Cardiothorac Surg 2016; 48: 137-41.

17. Kempfert J, Meuer A, Won-Keun K, et al. Comparison of two valve systems for transapical aortic valve implantation: a propensity score-matched analysis. Eur J Cardiothorac Surg 2016; 49: 486-92.

18. Schaefer U, Conradi L, Diement P, et al. Symetis Acurate TAVI: review of the technology, developments and current data with this self-expanding transcatheter heart valve. Minerva Cardioangiol 2015; 63: 359-69.

Received: 20.02.2017, accepted: 5.04.2017. 